\title{
RANCANG BANGUN SIMULASI PERGERAKAN HIGH LIFT DEVICE PADA PESAWAT
}

\author{
Lalu Giat Juangsah Putra ${ }^{1}$, James Siregar ${ }^{2}$, Dedy Syarif Qusyairi ${ }^{3}$ \\ Politeknik Negeri Batam \\ Program Studi Teknik Perawatan Pesawat Udara \\ Jl. Ahmad Yani, Batam Center, Batam 29461, Indonesia \\ E-mail: lalugiat@polibatam.ac.id
}

\begin{abstract}
Abstrak
High lift device yang paling banyak digunakan pada pesawat kecil maupun pesawat besar adalah flap. Flap dapat dipasang pada leading edge maupun trailing edge (hanya untuk pesawat besar) pesawat. Untuk membuat sebuah alat simulasi dibutuhkan rancang bangun dan juga sistem penggerak yang nantinya akan membentuk pergerakan seperti pada flap sesungguhnya. Sebagai mode penggerak, sistem yang dirancang pada alat simulasi flap ini akan menggunakan sistem elektronik yaitu motor servo yang akan dikendalikan oleh arduino. Sudut yang dibentuk oleh motor servo akan diberi penyesuaian terhadap sudut yang dibentuk oleh flap sesuai flap level. Alat simulasi flap ini dapat menghasilkan sudut yang dibentuk pada motor servo yaitu, $5^{\circ}, 14^{\circ}, 19^{\circ}, 25^{\circ}$ dan $30^{\circ}$ berhasil menggerakan flap pada flap level 0, 1, 2, 3 dan 4 baik pada mode pergerakan extend maupun retract.
\end{abstract}

Kata kunci: Arduino, Flap, Motor Servo, Simulasi, High lift device

\begin{abstract}
The most high lift device modifying, for small airplanes and large, is the wing flap. Flaps can be installed on the leading edge or trailing edge (only for large airplane) aircraft. To make a simulator, the design and also the drive system are needed which will form the movement as in the real flap. As a driving mode, the system which designed on this flap simulator will use an electronic system. By using a servo motor as a drive and Arduino as a microcontroller that will be programmed according to the planned movement. The flap simulator can produce angles formed on servo motors such as $5^{\circ}, 14^{\circ}, 19^{\circ}, 25^{\circ}$ and $30^{\circ}$ its moving flaps on flap level $0,1,2,3$ and 4 in extend and retract movement modes.
\end{abstract}

Keywords: Arduino, Flap, Servo Motor, Simulation, High lift device

\section{Pendahuluan}

Salah satu jenis high lift device yang paling banyak digunakan pada pesawat kecil maupun pesawat besar adalah flap. Flap dapat dipasang pada bagian traling edge dan leading edge (untuk pesawat besar) sayap pesawat [5]. Flap merupakan salah satu sistem yang terletak pada sayap pesawat terbang dan berfungsi untuk menambah luas penampang sayap pesawat. Penambahan luas penampang pada sayap bertujuan untuk meningkatkan gaya angkat pada pesawat [5]. Pergerakan flap selain untuk menambah luas penampang sayap juga untuk mengubah chamber pada sayap pesawat. Perubahan chamber pada sayap pesawat akan mengakibatkan peningkatan nilai gaya angkat dan gaya hambat pada sudut serang tertentu [1]. Flap umumnya digunakan pada saat pesawat lepas landas (take off) dan mendarat (landing). Flap digunakan pada kedua kondisi tersebut karena pada kondisi take off dan landing pesawat berkecepatan 
rendah sehingga pesawat memerlukan alat bantu untuk dapat mempertahankan gaya angkatnya [1].

Tujuan dari pembuatan alat simulasi flap ini adalah untuk memodelkan dan mensimulasikan mekanisme pergerakan alat simulasi flap sesuai dengan pergerakan flap pada pesawat. Alat ini juga dapat digunakan sebagai penunjang sarana pembelajaran untuk memperkenalkan fungsi dan cara kerja system flap yang ada di pesawat. Flap yang dibuat akan menggunakan sistem elektronik untuk menggantikan peran sistem hidrolik yang umumnya digunakan pada pesawat terbang.

\section{Metodologi Penelitian}

Dalam melakukan pembuatan alat simulasi flap ini terdapat beberapa tahapan yang akan dilakukan. Hal tersebut dilakukan untuk mendapatkan kesesuaian dari hasil rancang bangun dengan rancangan sistem penggerak yang akan dibuat, sehingga pergerakan yang dihasilkan sesuai dengan yang direncanakan. Langkah-langkah yang dilakukan seperti:

\section{A. Desain}

Flap yang di buat berjenis fowler flap dan memiliki 3 bagian, yaitu mounting flap, middle flap dan aft flap seperti yang tertera pada gambar 1. Spesifikasi yang akan digunakan pada proses pembuatan alat simulasi pergerakan high lift device, yaitu sebagai berikut:

a) Flap Mounting

$\begin{array}{ll}\text { Lebar } & : 53 \mathrm{~cm} \\ \text { Panjang } & : 35.5 \mathrm{~cm} \\ \text { Panjang track } & : 15 \mathrm{~cm}\end{array}$

b) Middle Flap

$\begin{array}{ll}\text { Lebar } & : 49 \mathrm{~cm} \\ \text { Panjang } & : 30.7 \mathrm{~cm} \\ \text { Panjang track } & : 6.5 \mathrm{~cm}\end{array}$

c) Aft Flap

$\begin{array}{ll}\text { Lebar } & : 42.2 \mathrm{~cm} \\ \text { Panjang } & : 30 \mathrm{~cm}\end{array}$

Luas penampang saat retract $\quad: 2303 \mathrm{~cm}^{2}$

Luas penampang saat extend $\quad: 3136 \mathrm{~cm}^{2}$ adalah autodesk inventor 2016. Hasil desain dapat dilihat pada gambar 1 .
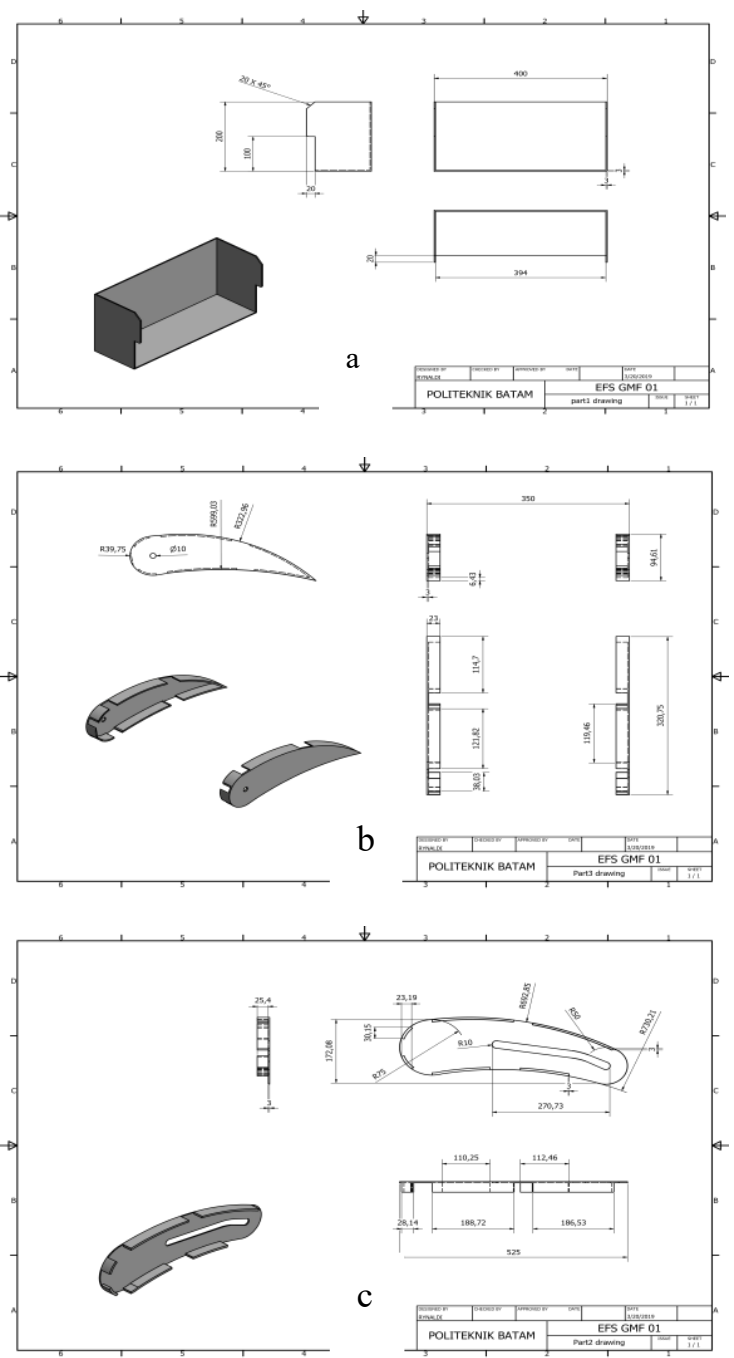

Gambar: 1 (a) Mounting Flap (b) Aft Flap (c) Mid Flap

B. Membuat design system control

Tahap ini akan memuat alur proses kerja dari sistem dengan komponen yang akan digunakan sehingga sistem sebagai pengendali dapat membuat pergerakan yang diinginkan seperti yang digambarkan pada gambar 2 [2].

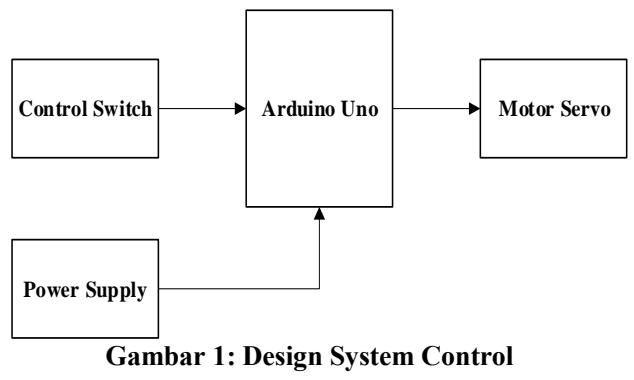

Aplikasi yang digunakan untuk membuat design 
Spesifikasi motor servo yang akan digunakan adalah sebagai berikut:

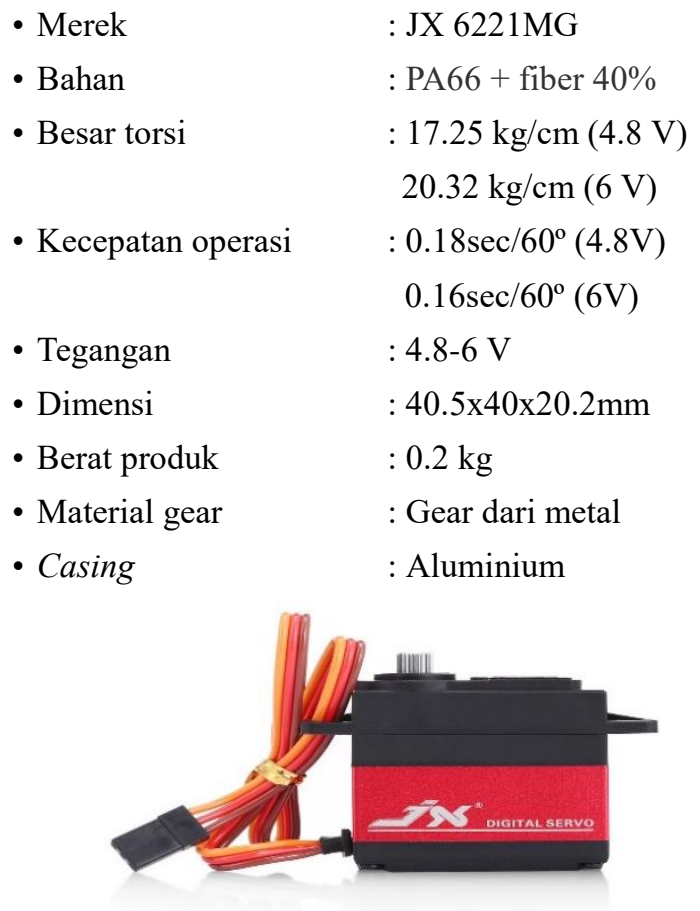

Gambar 2: Motor Servo JX 6221 MG

\section{Perakitan Sistem}

Perakitan sistem akan dilakukan melalui dua tahapan, yaitu perakitan sistem elektrikal dan sistem mekanikal.

\section{a. Sistem elektrikal}

Untuk menghasilkan pergerakan motor pada alat simulasi flap dibutuhkan sistem elektrikal. Sistem elektrikal yang akan digunakan adalah Arduino [4]. Arduino adalah alat elektronik atau papan rangkaian elektronik open source yang di dalamnya terdapat komponen utama, yaitu sebuah chip mikrokontroler. Arduino dapat membaca masukan dari control switch dan kemudian mengubahnya menjadi output berupa perintah untuk menggerakan motor. Arduino menjadi pusat kendali untuk mengatur semua mode pergerakan servo motor dengan menggunakan bahasa program yang dimasukan menggunakan software Arduino IDE [2]. Adapun beberapa komponen yang harus dipersiapkan untuk merakit sistem yang digunakan pada flap tersebut dapat diliat pada tabel I.
Tabel I

KOMPONEN DAN FUNGSINYA

\begin{tabular}{|c|l|}
\hline $\begin{array}{c}\text { Nama } \\
\text { Komponen }\end{array}$ & \multicolumn{1}{|c|}{ Fungsi } \\
\hline Arduino Uno & $\begin{array}{l}\text { Sebagai pusat perintah dan } \\
\text { kendali dari sistem }\end{array}$ \\
\hline Control Switch & $\begin{array}{l}\text { Sebagai selector untuk } \\
\text { menentukan pergerakan flap } \\
\text { yang di ingiinkan [4] }\end{array}$ \\
\hline $\begin{array}{c}\text { Servo Motor }+ \\
\text { Encoder }\end{array}$ & $\begin{array}{l}\text { Sebagai penggerak utama pada } \\
\text { alat simulasi flap, dan } \\
\text { mendeteksi posisi dari } \\
\text { pergerakan yang sudah di } \\
\text { tentukan oleh pusat kendali [3], } \\
\text { [4]. }\end{array}$ \\
\hline $\begin{array}{l}\text { Power Supply } \\
\text { Min.5V }\end{array}$ & $\begin{array}{l}\text { Sebagai sumber listrik yang akan } \\
\text { mensuplai arus kepada perangkat } \\
\text { sistem. }\end{array}$ \\
\hline $\begin{array}{l}\text { PC dengan } \\
\text { Arduino }\end{array}$ & $\begin{array}{l}\text { Untuk memasukkan program } \\
\text { sesuai dengan pergerakkan yang } \\
\text { dikehendaki. }\end{array}$ \\
\hline
\end{tabular}

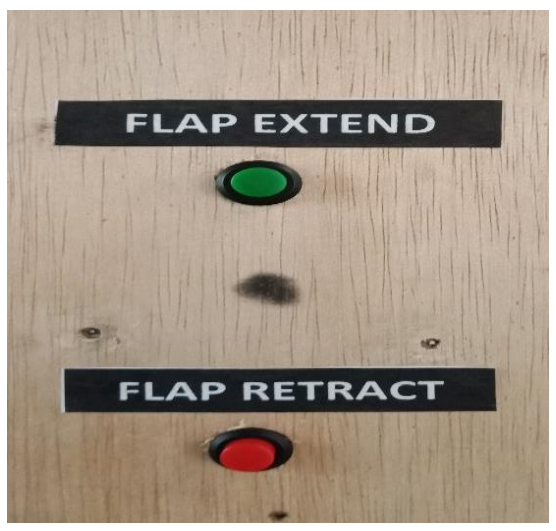

Gambar 4: Control Switch

\section{b. Sistem Mekanikal}

Untuk meneruskan pergerakan motor servo yang telah diprogram, dibutuhkan mekanisme sebagai penghubung antara motor servo dengan flap. Adapun beberapa komponen yang harus dipersiapkan untuk merakit sistem mekanikal yang digunakan pada flap dapat dilihat pada tabel II:

\section{Tabel II}

\section{KOMPONEN SISTEM MEKANIKAL}




\begin{tabular}{|c|l|}
\hline $\begin{array}{c}\text { Nama } \\
\text { Komponen }\end{array}$ & \multicolumn{1}{|c|}{ Fungsi } \\
\hline Main Rod & $\begin{array}{l}\text { Sebagai pendorong yang } \\
\text { langsung terhubung pada } \\
\text { poros motor servo }\end{array}$ \\
\hline Linkage Rod & $\begin{array}{l}\text { Sebagai penerus dorongan } \\
\text { dari Main Rod dan lansung } \\
\text { terhubung kepada titik } \\
\text { dorong pada flap }\end{array}$ \\
\hline $\begin{array}{l}\text { Linkage } \\
\text { Coupling }\end{array}$ & $\begin{array}{l}\text { Sebagai mekanisme } \\
\text { penyambung dorongan antar } \\
\text { linkage menuju titik dorong }\end{array}$ \\
\hline
\end{tabular}

Gambar komponen pada tabel II dapat dilihat pada gambar 5 .

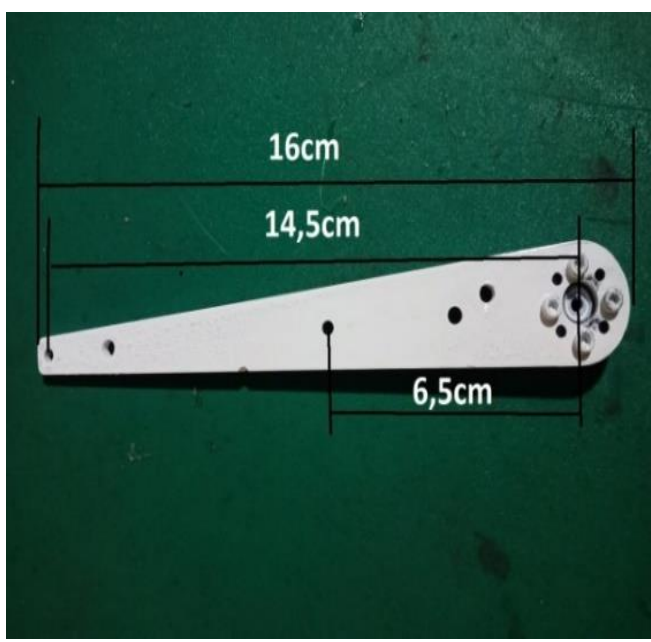

Gambar 5: Main Rod

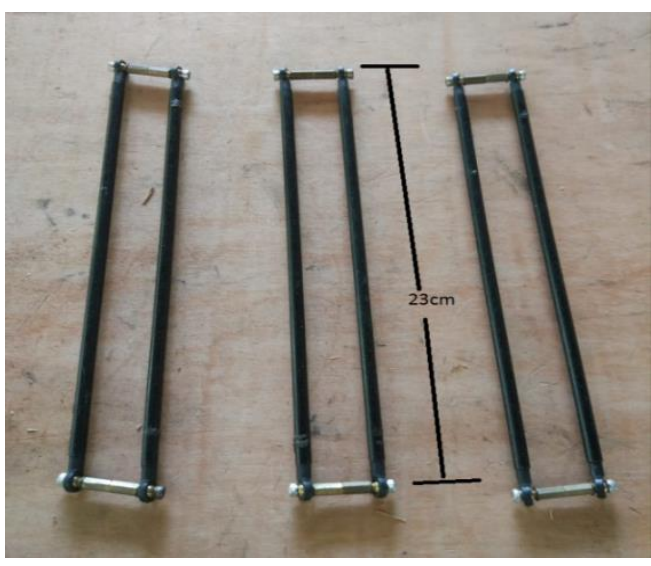

Gambar 6: Linkage Rod

\section{Pembahasan dan Analisa}

\subsection{Konsep Desain}

Konsep desain untuk sistem yang akan menggerakan alat simulasi flap ini akan menyesuaikan dari spesifikasi dari rancang bangun flap tersebut agar pergerakan yang diharapkan dapat terwujud. Hal yang menjadi pertimbangan diantaranya:

a. Beban maksimal yang akan di gerakkan oleh sistem penggerak.

Pada penghitungan beban, beban maksimal yang dapat digerakkan oleh motor servo bergantung kepada panjang lengan Main Rod. Untuk Jarak titik poros ke titik dorong untuk Mid Flap dan Aft Flap pada Main Rod adalah $14.5 \mathrm{~cm}$ dan $6.5 \mathrm{~cm}$. Motor servo mempunyai torsi sebesar $17.25 \mathrm{~kg} / \mathrm{cm}(4.8 \mathrm{~V})$ pada poros, sehingga torsi yang dihasilkan adalah :

$\frac{17.25 \mathrm{~cm} / \mathrm{kg}}{14.5 \mathrm{~cm}}=1.18 \mathrm{~kg}$ untuk Aft Flap

$\frac{17.25 \mathrm{~cm} / \mathrm{kg}}{6.5 \mathrm{~cm}}=2.6 \mathrm{~kg}$ untuk Mid Flap

b. Jarak pergerakan yang dihasilkan oleh sistem penggerak.

Jarak pergerakan yang mampu di hasilkan oleh sistem bergantung kepada panjang Main Rod dengan radius putarnya. Total panjang Main Rod dihitung dari poros adalah $15 \mathrm{~cm}$. Sehingga, apabila digerakan pada sudut $0^{\circ}$ sampai $180^{\circ}$ menjadi $30 \mathrm{~cm}$.

Berikut hasil dari perhitungan konsep desain.

Tabel III

Hasil perhitungan konsep desain

\begin{tabular}{|l|l|}
\hline $\begin{array}{l}\text { Beban total flap sebelum di } \\
\text { assembly }\end{array}$ & $: \pm 1.8 \mathrm{~kg}$ \\
\hline $\begin{array}{l}\text { Beban yang ditanggung untuk } \\
\text { pergerakkan Mid Flap }\end{array}$ & $: \pm 1.1 \mathrm{~kg}$ \\
\hline $\begin{array}{l}\text { Beban yang ditanggung untuk } \\
\text { pergerakkan Aft Flap }\end{array}$ & $: \pm 0.3 \mathrm{~kg}$ \\
\hline $\begin{array}{l}\text { Beban yang dapat di tanggung } \\
\text { oleh motor untuk menggerakan } \\
\text { mid flap }\end{array}$ & $: \pm 2.6 \mathrm{~kg}$ \\
\hline $\begin{array}{l}\text { Beban yang dapat di tanggung } \\
\text { oleh motor untuk menggerakan } \\
\text { aft flap }\end{array}$ & $: \pm 1.18 \mathrm{~kg}$ \\
\hline $\begin{array}{l}\text { Range pergerakkan yang dibuat } \\
\text { pada proses rancang bangun } \\
\text { (Flap track) }\end{array}$ & $: 16 \mathrm{~cm}$ \\
\hline $\begin{array}{l}\text { Range pergerakkan yang dapat } \\
\text { dihasilkan oleh motor } \\
\text { penggerak }\end{array}$ & $: 30 \mathrm{~cm}$ \\
\hline
\end{tabular}


c. Sudut yang akan dibentuk pada alat simulasi flap. Sudut yang akan dibentuk oleh sistem penggerak mengacu kepada rancang bangun dari flap tersebut, dimana titik flap level telah ditetapkan. Untuk mendapat sudut-sudut yang sesuai maka diperlukan proses perhitungan dan penyesuaian sistem terhadap flap. Sudut yang dibentuk pada alat yang dibuat, ditampilkan pada tabel IV.

Tabel IV

Sudut flap

\begin{tabular}{|c|c|c|}
\hline $\begin{array}{c}\text { Flap } \\
\text { Level }\end{array}$ & Sudut & Gambar \\
\hline 0 & $5^{\circ}$ & \\
\hline 1 & $14^{\circ}$ & \\
\hline 2 & $19^{\circ}$ & \\
\hline 3 & $25^{\circ}$ & \\
\hline & $30^{\circ}$ & \\
\hline
\end{tabular}

\subsection{Perhitungan dan Uji coba pergerakan} Flap

Perhitungan dilakukan dengan melakukan percobaan dan mengukur secara manual sudut yang dibentuk oleh pergerakan motor servo hingga mencapai dan sesuai dengan flap level yang telah ditentukan. Setelah melakukan perhitungan dan pengukuran, proses selanjutnya adalah penyesuaian dengan melakukan percobaan pergerakan untuk menarik data yang dihasilkan dari pergerakan alat simulasi flap.

Percobaan dilakukan sebanyak empat kali dengan mendapat hasil yang berbeda-beda. Empat kali percobaan tersebut bertujuan untuk mengambil rata rata pergerakan yang dihasilkan oleh sistem penggerak untuk menggerakan flap yang telah dibuat. Hasil dari percobaan yang dilakukan, dapat dilihat pada tabel V sampai tabel IX:

Tabel V

Percobaan pada posisi Flap lavel 0

\begin{tabular}{|l|c|c|c|c|}
\hline \multicolumn{1}{|c|}{ Percobaan } & I & II & III & IV \\
\hline Sudut Flap & $4^{\circ}$ & $5^{\circ}$ & $5^{\circ}$ & $5^{\circ}$ \\
\hline Sudut Motor Servo & $180^{\circ}$ & $180^{\circ}$ & $180^{\circ}$ & $180^{\circ}$ \\
\hline $\begin{array}{l}\text { Jarak yang di capai } \\
\text { Mid Flap (cm) }\end{array}$ & 0 & 0 & 0 & 0 \\
\hline $\begin{array}{l}\text { Jarak yang di capai Aft } \\
\text { Flap (cm) }\end{array}$ & 0 & 0 & 0 & 0 \\
\hline $\begin{array}{l}\text { Total luas penampang } \\
\text { yang dihasilkan }\left(\mathrm{cm}^{2}\right)\end{array}$ & 2303 & 2303 & 2303 & 2303 \\
\hline
\end{tabular}

Tabel VI

Percobaan pada posisi Flap lavel 1

\begin{tabular}{|l|c|c|c|c|}
\hline \multicolumn{1}{|c|}{ Percobaan } & I & II & III & IV \\
\hline Sudut Flap & $12^{\circ}$ & $14^{\circ}$ & $14^{\circ}$ & $13^{\circ}$ \\
\hline Sudut Motor Servo & $125^{\circ}$ & $125^{\circ}$ & $125^{\circ}$ & $125^{\circ}$ \\
\hline $\begin{array}{l}\text { Jarak yang di capai } \\
\text { Mid Flap (cm) }\end{array}$ & 2 & 2 & 2 & 2 \\
\hline $\begin{array}{l}\text { Jarak yang di capai } \\
\text { Aft Flap (cm) }\end{array}$ & 2,5 & 2,5 & 2,5 & 2,5 \\
\hline $\begin{array}{l}\text { Total luas penampang } \\
\left.\text { yang dihasilkan (cm }{ }^{2}\right)\end{array}$ & 2401 & 2401 & 2401 & 2401 \\
\hline
\end{tabular}

Tabel VII

Percobaan pada posisi Flap lavel 2

\begin{tabular}{|l|c|c|c|c|}
\hline \multicolumn{1}{|c|}{ Percobaan } & I & II & III & IV \\
\hline Sudut Flap & $19^{\circ}$ & $20^{\circ}$ & $19^{\circ}$ & $19^{\circ}$ \\
\hline $\begin{array}{l}\text { Sudut Motor Servo } \\
95^{\circ}\end{array}$ & $95^{\circ}$ & $95^{\circ}$ & $95^{\circ}$ \\
\hline $\begin{array}{l}\text { Jarak yang di capai Mid } \\
\text { Flap (cm) }\end{array}$ & 4,8 & 4.8 & 5 & 5 \\
\hline $\begin{array}{l}\text { Jarak yang di capai Aft } \\
\text { Flap (cm) }\end{array}$ & 3,5 & 3.5 & 3.2 & 3.2 \\
\hline
\end{tabular}




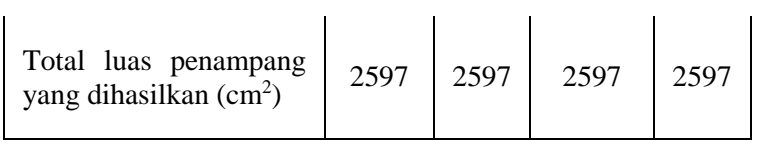

Tabel VIII

Percobaan pada posisi Flap lavel 3

\begin{tabular}{|l|c|c|c|c|}
\hline \multicolumn{1}{|c|}{ Percobaan } & I & II & III & IV \\
\hline Sudut Flap & $25^{\circ}$ & $25^{\circ}$ & $24^{\circ}$ & $24^{\circ}$ \\
\hline $\begin{array}{l}\text { Sudut Motor Servo } \\
72^{\circ}\end{array}$ & $72^{\circ}$ & $72^{\circ}$ & $72^{\circ}$ \\
\hline $\begin{array}{l}\text { Jarak yang di capai } \\
\text { Mid Flap (cm) }\end{array}$ & 7,7 & 7,7 & 7.8 & 7.8 \\
\hline $\begin{array}{l}\text { Jarak yang di capai Aft } \\
\text { Flap (cm) }\end{array}$ & 5,7 & 5,7 & 6 & 6 \\
\hline $\begin{array}{l}\text { Total luas penampang } \\
\left.\text { yang dihasilkan (cm }{ }^{2}\right)\end{array}$ & 2891 & 289 & 2897 & 289 \\
\hline
\end{tabular}

Tabel IX

Percobaan pada posisi Flap lavel 4

\begin{tabular}{|l|c|c|c|c|}
\hline \multicolumn{1}{|c|}{ Percobaan } & I & II & III & IV \\
\hline Sudut Flap & $29^{\circ}$ & $28^{\circ}$ & $30^{\circ}$ & $30^{\circ}$ \\
\hline $\begin{array}{l}\text { Sudut Motor Servo } \\
40^{\circ}\end{array}$ & $40^{\circ}$ & $40^{\circ}$ & $40^{\circ}$ \\
\hline $\begin{array}{l}\text { Jarak yang di capai Mid } \\
\text { Flap (cm) }\end{array}$ & 9.9 & 9.9 & 10 & 10 \\
\hline $\begin{array}{l}\text { Jarak yang di capai Aft } \\
\text { Flap (cm) }\end{array}$ & 6 & 6 & 6 & 6 \\
\hline $\begin{array}{l}\text { Total luas penampang } \\
\left.\text { yang dihasilkan (cm }{ }^{2}\right)\end{array}$ & 3136 & $\begin{array}{c}313 \\
6\end{array}$ & 3136 & $\begin{array}{c}6 \\
6\end{array}$ \\
\hline
\end{tabular}

Setelah melakukan empat kali percobaan perhitungan dan penyesuaian dari sudut motor servo untuk mencapai flap level yang sudah, maka dapat diambil kesimpulan sebagai berikut:

Tabel X

Kesimpulan hasil percobaan Flap level 0-4

\begin{tabular}{|c|c|c|c|c|c|}
\hline $\begin{array}{c}\text { Posisi/Flap } \\
\text { Level }\end{array}$ & $\mathbf{0}$ & $\mathbf{1}$ & $\mathbf{2}$ & $\mathbf{3}$ & $\mathbf{4}$ \\
\hline Sudut Flap & $5^{\circ}$ & $14^{\circ}$ & $19^{\circ}$ & $25^{\circ}$ & $30^{\circ}$ \\
\hline $\begin{array}{c}\text { Sudut } \\
\text { Motor } \\
\text { Servo }\end{array}$ & $180^{\circ}$ & $125^{\circ}$ & $95^{\circ}$ & $72^{\circ}$ & $40^{\circ}$ \\
\hline $\begin{array}{c}\text { Jarak yang } \\
\text { di capai } \\
\text { Mid Flap } \\
\text { (cm) }\end{array}$ & 0 & 2 & 5 & 8 & 10 \\
\hline
\end{tabular}

\begin{tabular}{|c|c|c|c|c|c|}
$\begin{array}{c}\text { Jarak yang } \\
\text { di capai } \\
\text { Aft Flap } \\
(\mathrm{cm})\end{array}$ & 0 & 2,5 & 3,2 & 5,5 & 6 \\
\hline $\begin{array}{c}\text { Total luas } \\
\text { penampang } \\
\text { yang } \\
\text { dihasilkan } \\
\left(\mathrm{cm}^{2}\right)\end{array}$ & 2303 & 2401 & 2597 & 2891 & 3136 \\
\hline
\end{tabular}

Berdasarkan hasil percobaan yang ditampilkan pada tabel X, dapat dilihat bahwa adanya pertambahan luas penampang pada sayap akibat pergerakan flap. Pada posisi flap level $0\left(5^{\circ}\right)$ luas penampang yang dihasilkan $2303 \mathrm{~cm}^{2}$ sedangkan pada posisi flap level 1 (14') luas penampang yang dihasilkan $2401 \mathrm{~cm}^{2}$.

\subsection{Pengoperasian dan Cara Kerja Sistem Penggerak}

Sistem yang akan menggerakan alat simulasi flap ini mempunyai urutan tata cara mengoperasikan dan cara kerja hingga menghasilkan gerakan.

\subsubsection{Cara Mengoperasikan}

Untuk mengoperasikan alat simulasi flap ini perlu mengetahui langkah langkah sebagai berikut:

- Hubungkan power supply ke sumber listrik

- Secara otomatis motor akan menuju titik flap level 0

- Untuk mendapatkan pergerakan extend menuju flap level yang lebih besar, tekan switch berwarna hijau satu kali untuk setiap pertambahan flap level nya. Pastikan bahwa posisi disetiap level sudah tercapai secara sempurna terlebih dahulu.

- Untuk mendapatkan pergerakkan retract menuju flap level yang lebih kecil, tekan switch berwarna merah satu kali untuk setiap berkurangnya flap level. Pastikan bahwa posisi disetiap level sudah tercapai secara sempurna terlebih dahulu.

- Untuk menghasilkan pergerakan dan sudut yang sesuai dengaan masing masing flap level, hindari menahan tombol secara terus menerus.

\subsubsection{Cara Kerja Sistem Pengggerak}

Arduino sebagai pusat kendali pergerakkan motor servo diberi program dengan perintah kerja sesuai dengan rancangan pergerakkan yang akan dihasilkan,yaitu [2]:

- Arduino diprogram untuk membaca posisi $180^{\circ}$ 
sebagai posisi awal servo motor sebelum diberi perintah lanjutan.

- Arduino diprogram membaca tombol hijau yang ditekan sebagai perintah motor servo untuk memperkecil sudut yang di mulai dari sudut $180^{\circ}$, $125^{\circ}, 95^{\circ}, 72^{\circ}, 40^{\circ}$ secara berurutan untuk tiap satu kali tekan.

- Arduino diprogram membaca tombol merah yang ditekan sebagai perintah motor servo untuk memperbesar sudut motor servo yang di mulai dari sudut $40^{\circ}, 72^{\circ}, 95^{\circ}, 125^{\circ}, 180^{\circ}$ secara berurutan untuk tiap satu kali tekan.

- Arduino diprogram untuk tetap dapat melakukan perintah dari tombol hijau dan merah dengan tidak harus sampai pada sudut maksimal extend atau maksimal retract terlebih dahulu.

- Arduino diprogram untuk dapat tetap mempertahankan motor servo pada posisi sudut yang telah ditentukan disetiap flap level sebelum mendapat perintah dari tombol hijau atau tombol merah.

\section{Kesimpulan}

Berdasarkan data utama flap yang sudah dirancang, maka digunakanlah motor servo bertipe JX6221MG sebagai alat penggerak alat simulasi flap yang mana pergerakkan motor servo tersebut dikendalikan oleh arduino yang telah diprogram sesuai dengan flap level yang dimaksud. Dari hasil percobaan dan penyesuaian dihasilkan lima sudut dari motor servo. Sudut yang dibentuk pada motor servo yaitu, $5^{\circ}, 14^{\circ}, 19^{\circ}, 25^{\circ}$,dan $30^{\circ}$ berhasil menggerakan flap pada flap level 0, 1, 2, 3, dan 4. Flap level 0 disebut dengan titik retract dan flap level 4 disebut dengan titik extend. Luas penampang flap yang dapat dibentuk yaitu pada Flap level 0 sebesar $2303 \mathrm{~cm}^{2}$, Flap level 1 sebesar $2401 \mathrm{~cm}^{2}$, Flap level 2 sebesar $2597 \mathrm{~cm}^{2}$, Flap level 2 sebesar $2891 \mathrm{~cm}^{2}$, dan Flap level 0 sebesar $3136 \mathrm{~cm}^{2}$.

\section{Daftar Pustaka}

[1] Jeppesen. (2016). Airframe Technician Textbook. USA: Englewood.

[2] Kadir, A. (2017). Pemrograman Arduino \&
Android Menggunakan App Inventor. Jakarta: PT Elex Media Komputindo.

[3] Samuel, H Saroinsong. dkk. 2018. Rancang Bangun Wahana Pesawat Tanpa Awak (Fixed Wing) Berbasis Ardupilot. Jurnal Teknik Elektro dan Komputer. Vol. 7, 1.

[4] Albayumi, Usep Ali. Dkk. 2018. Perancangan prototype landing gear system dan monitoring pergerakan landing gear system pesawat terbang menggunakan mikrokontroler. Universitas Telkom program studi S1 teknik elektro.

[5] https://www.faa.gov/regulations_policies/hand books_manuals/aircraft/media/amt_general_ha ndbook.pdf 